\title{
PEDAGOGIA DO IMAGINÁRIO E FUNÇÃO IMAGINANTE: REDEFININDO O SENTIDO DA EDUCAÇÃO ${ }^{1}$
}

\author{
PEDAGOGY OF THE IMAGINARY AND THE \\ IMAGINING FUNCTION: REDEFINING THE \\ MEANING OF EDUCATION ${ }^{2}$
}

\author{
Maria Cecília Sanchez TEIXEIRA*
}

\begin{abstract}
Resumo: O objetivo deste artigo é contribuir para a reflexão sobre a importância do imaginário na educação e oferecer pistas para uma pedagogia do imaginário. Numa perspectiva durandiana, considera-se que, se através do imaginário nos reconhecemos como humanos e atribuímos sentido às coisas e ao mundo, só uma pedagogia que valorize o "imaginário aprendente", poderá efetivamente se apropriar do seu sentido original de construção da cultura por meio da educação. Tendo como fio condutor a interrogação sobre a possibilidade de se ensinar alguém a se comportar imaginativamente, desenha-se em breves traços uma pedagogia do imaginário como metáfora do processo de humanização por meio da função imaginante.
\end{abstract}

Palavras-chave: Pedagogia. Imaginário. Pedagogia do imaginário.

Abstract: The aim of this article is to contribute to the reflection about the importance of the imaginary in education and provide suggestions to the pedagogy of the imaginary. From a perspective based on Durand's concepts, the article considers that if by means of the imaginary we recognize ourselves as human beings and we attribute meaning to things and to the world, only a pedagogy that values the "learning imaginary" will be able to effectively re-appropriate its original meaning of culture construction via education. Questioning the possibility of teaching people to behave imaginatively, the article designs a pedagogy of the imaginary as a metaphor of the process of humanization by means of the imagining function.

Keywords: Pedagogy. Imaginary. Pedagogy of the imaginary.

${ }^{1}$ Palestra proferida no II Colóquio Internacional Imaginário e Educação, UFF, 3/8/2006.

${ }^{2}$ Lecture held at the II Imaginary and Education International Colloquium, UFF, 3/8/06.

* Professora do Programa de Pós-Graduação da FEUSP, Coordenadora do Centro de Estudos do Imaginário, Cultura e Educação CICE/FEUSP. cila@usp.br

Olhar de professor, Ponta Grossa, 9(2): 215-227, 2006. 
Por isso, nós que acabamos de dar um lugar tão belo à imaginação, pedimos modestamente que se saiba dar lugar à cigarra ao lado do frágil triunfo da formiga (...) É-nos assim evidente que uma pedagogia da imaginação se impõe ao lado da cultura física e da do raciocínio (...) Impõe-se então uma educação estética, totalmente humana, como educação fantástica à escala de todos os fantasmas da humanidade.

(Gilbert Durand)

Hoje pretendo partilhar com vocês algumas reflexões sobre a contribuição dos estudos do imaginário para a educação e, de certa forma, ensaiar uma resposta para aqueles que nos cobram uma proposta pedagógica que contemple o imaginário.

Nos últimos anos, temos criado (ou nos apropriado) e divulgado diversas expressões como: educação fática (BADIA\& CARVALHO, 2002), pedagogia do imaginário (JEAN,1979; DUBORGEL, 1992; JACQUETMONTREUIL, 1998; ARAÚJO \& ARAÚJO, 2004), educação do imaginário, educação da alma, entre outros. Muitas vezes, deslocadas do contexto teórico no qual foram criadas, tais expressões passaram a ser veiculadas de forma banalizada e simplificadora, tornando-se lugares comuns, perdendo o seu significado. Caímos no que Durand (1996) chama de "armadilha das palavras".

Como somos "tecelões de palavras" (POSTMAN, 2005) precisamos cuidar para que as que utilizamos não se transformem em meros jargões. Por isso, julguei conveniente aproveitar esta oportunidade para explicitar melhor o que podemos entender por pe- dagogia do imaginário, expressão polêmica mesmo entre os que trabalham com o imaginário.

E por que escolhi pedagogia do imaginário e não qualquer das outras expressões, muitas vezes empregadas como sinônimos?

Porque, no meu entender, precisamos reabilitar e re-significar a pedagogia, que no processo de extrema racionalização pelo qual passou, perdeu todo seu sentido original. Derivada de Paidéia, que significa a própria cultura construída a partir da educação, ela se transformou em ciência que estuda o processo educativo do ponto de vista da relação pedagógica. Identificada com tecnicismo, ela foi adquirindo, entre nós, conotações negativas nos últimos anos. No entanto, descartar de plano o termo pedagogia, como muitos têm feito, simplesmente pelas associações negativas que ele suscita; seria, como diz o ditado popular: "jogar fora a criança com a água do banho".

Então, é minha intenção explicitar as diversas acepções de pedagogia do imaginário, identificando primeiramente o que ela não é, para depois esboçar o que ela é ou poderia ser. 
Fiel ao meu mestre Paula Carvalho, penso que o ponto de partida de qualquer diálogo é explicitar os conceitos que utilizamos, lembrando que estes têm, segundo Jung (apud HILLMAN, 1990), valor terapêutico, na medida em que são maneiras de tomar, abarcar e compreender. Se, como diz esse autor, pensamento e sentimento conceituais servem à consciência psicológica, esperemos que, guardadas as devidas proporções, o conceito de pedagogia do imaginário possa servir à consciência pedagógica. Mas, ao mesmo tempo, não podemos depositar todas as nossas esperanças nesta conceituação, porque no seu furor explicativo, os conceitos limitam, cortam e excluem.

Nesta reflexão, faço um duplo movimento, ao mesmo tempo de contenção e de ampliação deste conceito.Esclareço, pois, que não pretendo nem apresentar definições fechadas e, muito menos, propor um modelo de ação, um manual ou uma cartilha de pedagogia do imaginário.

O fio condutor da nossa conversa será a seguinte questão: é possível ensinar alguém a se comportar imaginativamente? Em outros termos: é possível estimular a função imaginante na escola? Se a resposta for positiva, poderemos pensar em uma pedagogia do imaginário? Mas, se for negativa, vamos concluir que desenvolver o imaginário não é uma tarefa para a escola?

O educador americano Neil Postman (2005), em seu livro "O fim da educação", afirma que definições, perguntas e metáforas são os três elementos mais potentes com que a linguagem humana constrói uma cosmovisão. Então, valendo-me dessa idéia, pretendo aqui, a partir destas questões e das inúmeras definições de pedagogia do imaginário, pensá-la como uma metáfora, através da qual possamos redefinir o sentido da educação escolar.

É, pois, minha intenção mostrar a importância do imaginário para a pedagogia, qualquer que seja ela e indicar pistas e possibilidades de uma educação escolar que valorize a função imaginante do aluno, o "imaginário aprendente" (JACQUET MONTREUIL, 1998).

O tom será eminentemente pedagógico, embora não seja possível tratar do imaginário sem o concurso de outras áreas de conhecimentos afins, cujos conceitos foram incorporados aos estudos do imaginário, lembrando com Durand (1996) que o imaginário é um lugar de "entre-saberes".

Parto do pressuposto de que, numa perspectiva durandiana, que é a nossa, é através do imaginário que nos reconhecemos como humanos, conhecemos o outro e apreendemos a realidade múltipla do mundo. É o imaginário que, por meio do processo de simbolização, define as competências simbólico-organizacionais dos indivíduos e dos grupos, organizando as experiências e as ações humanas. São os processos de simbolização que permitem ao ser humano assumir 
sua humanidade, tomar consciência da condição própria dos seres vivos, ou seja, do seu destino mortal. Para Durand (1967), o universo humano é simbólico e só é "humano" na medida em que o homem atribui sentido às coisas e ao mundo.

Talvez, ao fim e ao cabo, não consiga responder conclusivamente às questões aqui propostas. Nem tenho essa pretensão. Quero sugerir, no entanto, que, sem elas como norte, não iremos a lugar nenhum neste vasto território dos estudos do imaginário.

\section{IMAGINÁRIOEPEDAGOGIA}

Relacionando imaginário e pedagogia, comecemos por esta última. Segundo Durand (1994), a pedagogia tal como a conhecemos hoje é filha do positivismo que, por sua vez, nasceu do casamento entre a factualidade do empirismo e o rigor iconoclasta do racionalismo clássico. Dessa forma, é natural que seja vista com desconfiança por aqueles que trabalham com o imaginário.

Mas, é importante lembrar que a pedagogia carrega um duplo sentido: 1) numa concepção restrita, pedagogia diz respeito aos métodos, técnicas e estratégias, ao saber-fazer, às competências e experiências necessárias à transmissão de conhecimentos, identificando-se com pedagogia escolar, a qual se sistematiza em um discurso institucionalizado, cuja função é transmitir informações e legitimar a verdade; 2) numa concepção amplia- da, ela ultrapassa os muros da escola, atingindo toda sociedade, podendo configurar-se como um sistema pedagógico, cujo papel é imprimir a marca da cultura na humanidade.

Evidentemente, quando se pensa em uma pedagogia do imaginário, ela pode ser considerada em ambos os sentidos. Mas, é pelo último, que inicio a minha reflexão e assim relembrando o conceito de bacia semântica de Durand (1994).

Este autor utiliza uma metáfora potomológica para se referir à circulação espaço-temporal dos mitos e mostrar como uma sociedade oscila, necessariamente, entre "diástoles" e "sístoles", ligadas a mitos contraditórios. Esta tensão dialética, entre narrativas míticas, sempre em busca de equilíbrio, é fonte evolutiva de mudanças. Os mitos dominantes, ao se sentirem ameaçados, condensamse cada vez mais em códigos, regras, convenções; acelerando, porém e, portanto, seu esgotamento. Ao mesmo tempo, os mitos marginalizados começam a mostrar sua cara.

A dominância mítica de um certo regime arquetípico de imagens num dado momento exerce uma "pressão pedagógica", que define o "espírito reinante" (DURAND, 1997), as visões de mundo, as ideologias, as utopias, os sistemas pedagógicos. Entendo que Durand utiliza aqui "pressão pedagógica” para mostrar o caráter educativo dos mitos.

Nessa perspectiva ampliada, podemos, então, considerar a pedago- 
gia como o resultado de projeções imaginárias e míticas. Estas determinam modos de vida, que são codificadas em conceitos socializados e traduzidos em sistemas pedagógicos.

Durand (1997) se refere mesmo a uma "pedagogia social dos arquétipos", que orienta e conduz uma sociedade ao longo de uma bacia semântica, legitimando, justificando e integrando visões de mundo e idéias dominantes de uma sociedade. Nesse sentido, estamos sempre sob o jugo de uma pedagogia do imaginário, para o bem ou para o mal, quer queiramos ou não. É essa derivação pedagógica que, de acordo com o autor, modela os arquétipos em símbolos pelo contexto social. É ela a responsável pela difusão dos arquétipos numa época dada, na consciência de um grupo.

Pois bem, tanto em sua acepção restrita, como na ampliada, o que atribui caráter pedagógico ao conjunto de sistematizações e normatizações, seja da vida escolar, seja da social, é exatamente sua derivação das idéias dominantes na sociedade, erigidas como "verdades" que justificam, legitimam e integram, por meio do "discurso oficial", os grupos, as culturas, as sociedades. Em ambas temos um corpus que é veiculado pelo discurso pedagógico, discurso no qual se fazem ouvir as "vozes pedagógicas" dos mitos, como bem aponta Araújo \& Araújo (2004).

As mensagens pedagógicas das vozes míticas influenciam e inspiram de modo pregnante a realização de narrativas educacionais que estão prenhes de vestígios míticos ainda que reduzidos à condição de simples metáforas, porque foram vítimas da racionalização extrema, na modernidade. Mas, como esta se esgota e, com ela seus mitos diretores, podemos esperar que novas "vozes pedagógicas" se façam ouvir, redefinindo o sentido da pedagogia e da educação.

Se a pedagogia remete ao "como fazer", o imaginário remete ao sentido, à finalidade, porque é por meio dele que organizamos nossas experiências e atribuímos sentido à vida. Então, uma pedagogia do imaginário, independentemente do "como fazer", remeterá sempre ao sentido que se quer imprimir à educação e à vida.

Já se tornou lugar comum, sobretudo a partir da publicação do livro "Os sete saberes necessários à educação do futuro", de Edgar Morin (2001), afirmar-se que o objetivo da educação é ensinar a condição humana, embora isto não seja nenhuma novidade. Fétizon (2002) desde a década de 60, na esteira de Sócrates e Gusforf, vem enfatizando que a educação é o processo de auto-construção da humanidade no sujeito. Nenhum de nós discorda disso, muito pelo contrário. No entanto, este objetivo ainda está descolado de uma narrativa que dê sentido a essa ação de ensinar a condição humana. Eu diria que propostas como estas começam a esboçar o rascunho de novas narrativas orientadoras da educação e da 
escolarização. São válidas e, portanto, é bom que comecem a ser veiculadas.

Embora filha do humanismo, a pedagogia prometéica dominante na modernidade não conseguiu ensinar a condição humana. Com seu modo heróico de ser, provocou uma inflação do espírito que foi compensada por uma inferioridade de sentimento. Hillman, (1990) citando Jung, referese a uma subnutrição do sentimento pessoal. Araújo \& Araújo (2004) ao criticar esta pedagogia nos faz psiquiatricamente aberrantes, porque hipercerebrais e devotados à abstração desencarnada e necrófila. Termos pesados demais para descrever o resultado dessa pedagogia? Creio que não.

Essa subnutrição do sentimento, da sensibilidade e da imaginação já foi exaustivamente mostrada pelos críticos da modernidade e pelos estudiosos do imaginário, de modo que, aqui, quero apenas lembrar das suas conseqüências pedagógicas: 1) a domesticação da imagem, colocada a serviço do ensino, como mais um recurso pedagógico, transformando, por exemplo, a literatura em mero exercício escolar; 2) as simplificações deformantes das imagens de contos, canções e poesias, sob o argumento de que são deseducativos, violentos ou politicamente incorretos; 3 ) a dosagem da fantasia, em razão da crença de que esta, em doses exageradas, poderia afastar a criança e o jovem da realidade; 4) o uso pervertido da imagem (DUBORGEL, 1992), que anexada à intenção de informar sobre as coisas é utilizada simplesmente como imagem-espelho.

Se desde Aristóteles a imagem é desvalorizada e descartada em razão da sua ambigüidade, é com Descartes que o fosso entre razão e imaginação se aprofunda. O privilégio pedagógico é atribuído à percepção e ao conceito, em detrimento da imaginação. O símbolo perde a sua plurivocidade, torna-se sintema. No processo de sintematização, o símbolo se empobrece semanticamente, porque a equivo-cidade e a espessura de sentido cedem lugar ao conceptualismo que se dirige para a univocidade (DURAND, 1988). Esse deslizamento empobrecedor da imagem ao conceito pode ser poeticamente ilustrado por Manoel de Barros (2001, p. 25), quando diz:

O rio que fazia uma volta atrás de nossa casa era a imagem de um vidro mole que fazia uma volta atrás de casa.

Passou um homem depois e disse: Essa volta que o rio faz por trás de sua casa se chama enseada.

Não era mais a imagem de uma cobra de vidro que fazia uma volta atrás de casa.

Era uma enseada.

Acho que o nome empobreceu a imagem. 
Mas as vozes pedagógicas de Prometeu e de outros mitos diurnos ${ }^{2}$ estão emudecendo. A permanente circulação mítica sugere que a bacia semântica da modernidade está se esgotando porque seus mitos atingem seu ponto de saturação, deixando-se penetrar por outras correntes míticas, anunciadoras de outros mitos, de outras visões de mundo, geralmente aquelas que haviam sido reprimidas e permaneciam na sombra.

No eterno movimento do devir, um mundo está morrendo e outro está nascendo. Nesse mundo em gestação, as narrativas míticas que atribuíam sentido à vida já não servem às experiências humanas. As metáforas, imagens e símbolos já não conseguem mais comunicar os sentimentos e significados que tinham originalmente no tempo em que foram criadas. Estão fora de lugar. As significações abandonaram suas antigas carapaças, mas ainda não encontraram um novo invólucro (MORIN, 2002) e, enquanto os novos mitos não se fortalecem, há um grande vazio de sentido. Sentido que é buscado no culto exacerbado do corpo, nas falsas promessas de juventude eterna, nas drogas, no prazer "fast food", que dominam o que Lipovestky (2005) chamou de "A era do vazio". Vazio de narrativas que dêem sentido à vida, à educação.

A finalidade das narrativas míticas é criar uma cultura comum que dê sentido ao mundo. Sem uma narrativa a vida não tem sentido. Como mitologia, a narrativa é, de acordo com Campbell (2001), um sistema de imagens que dota a mente e os sentimentos de um sentido de participação num campo de significados para o bem e para o mal. Porque, dependente do vigor metafórico de seus símbolos, uma narrativa pode gerar tanto visões equilibradas de mundo, utopias agregadoras como fundamentalismos retrógrados.

Fazendo um parêntesis, lembro que uma crença sustentada com muito vigor, uma crença que exclui a possibilidade de tolerância com outros deuses, pode redundar em fanatismo psicopata e, a história atual está cheia de exemplos de fundamentalismos geradores de guerras santas. Tal perigo pode ser constatado no filme/ documentário: A arquitetura da destruição, de Peter Cohen sobre o nazismo. Neste filme ele mostra que o nazismo não propõe apenas uma nova política ou uma nova forma de governo ou de vida social, mas é uma narrativa detalhada sobre uma certa concepção de mundo, de homem, de educação que, transformada em doutrina, requer dos seus seguidores uma fé inabalável.

Então, no mundo que nasce, que correntes míticas afloram, ainda que

\footnotetext{
${ }^{2}$ Diurno aqui se refere ao regime de imagens no qual a imaginação heróica combate os monstros hiperbolizados por meio de símbolos antitéticos: as trevas são combatidas pela luz e a queda pela ascensão. Põe em ação imagens e temas de luta (DURAND, 1997).
}

Olhar de professor, Ponta Grossa, 9(2): 215-227, 2006. $\overline{221}$ 
timidamente? Que deuses se fazem ouvir no panteão pós-moderno? Penso que já é possível identificar as "vozes pedagógicas" do sedutor, amoroso e pervertido Eros, do desordeiro, exuberante e pródigo Dioniso, do ardiloso, conciliador e infantil Hermes, todos mitos noturnos ${ }^{3}$ que retornam após longo tempo adormecidos no inconsciente coletivo e que têm, em comum, atributos como a ligação, a coesão, a aproximação, a conciliação de contrários.

É nesse quadro, aqui rapidamente esboçado, que se coloca a pedagogia do imaginário, não como a salvação da escola, mas como uma metáfora prenhe de possibilidades.

\section{PISTAS PARAUMAPEDAGOGIA DOIMAGINÁRIO}

Em seu livro já citado, Postman (2005) afirma que a escola precisa de narrativas as quais lhe dêem sentido e razão de ser. Se concordarmos com ele e postularmos a necessidade de narrativas que possam ser compartilhadas pelos educadores, que sejam fonte de identidade e de valores transcendentes, devemos nos perguntar agora: pode a escola contribuir para a criação de tais narrativas ou ela será sempre uma mera reprodutora de mitos?

De acordo com este autor, os mi- tos que unem uma nação e dão sentido à idéia de uma educação pública não são escritos pelos professores. No caso dos Estados Unidos, e creio que vale para nós num mundo globalizado, são os músicos, os cineastas e até os homens ocos reunidos em volta das piscinas de Beverly Hills. As escolas, no seu entender, não são organizadas para criar narrativas. Elas as recolhem, amplificam, distribuem e enaltecem, mas nada criam. A se crer na teoria durandiana realmente a escola como todas as instituições sociais sofre a pressão pedagógica dos arquétipos.

Então, se a escola não é uma criadora de mitos, esperamos que, quando muito, por meio de uma pedagogia do imaginário, ela possa contribuir para a veiculação de mitos mais agregadores e mais equilibradores do imaginário social.

$\mathrm{Na}$ tentativa de pensar a pedagogia do imaginário como metáfora, precisamos antes passar pelas suas definições e, face às confusões entre os termos a que me referi no início, creio ser necessário começar pelo que aparentemente ela não é.

Uma pedagogia do imaginário não é um processo terapêutico, portanto, mesmo que, no horizonte distante, ela possa contribuir para o processo de individuação, este não é o seu fim imediato. Processo psíquico lento e gra-

${ }^{3}$ Noturno diz respeito a uma atitude imaginativa que, sob o signo da conversão e do eufemismo, inverte os valores simbólicos das imagens do tempo. Nesse regime os mitos tingem de desejo o próprio destino que não é mais combatido, mas assimilado (DURAND, 1997).

222 Olhar de professor, Ponta Grossa, 9(2): 215-227, 2006. 
dual de crescimento e maturação, o caminho da individuação leva à realização mais completa das qualidades coletivas do ser humano. Jung (1987) acredita que é a realização das qualidades individuais o fator determinante de um melhor rendimento social.

A pedagogia do imaginário também não é uma pedagogia do lúdico. Ela não deve ter como objetivo apenas o "aprender brincando", como se os únicos valores a serem reforçados fossem o prazer e o estímulo dos sentidos. Da mesma forma, não pode ser uma pedagogia da sedução que se vale da arte para reforçar o hedonismo reinante nas culturas pós-modernas. A propósito da supervalorização da estética por Maffesoli, Paula Carvalho (1987) desde a década de 80 já nos alertava para o risco de a estética deslizar para o puro esteticismo, que, no seu entender, significa colocar a estética para além da ética.

A pedagogia do imaginário também não se confunde com a educação fática, embora possa se valer dela. Paula Carvalho (1998), criador desse conceito, entende a educação fática como formação de sensibilidade de teor (mytho) poiético, como intervenção problemática na culturanálise de grupos empíricos, ou de grupalidades internas. A educação fática visa à cultura e à educação da alma através do engendramento dos símbolos do simesmo. Paula Carvalho (1998) propõe o fático como fator simbólico que é, em última instância, a "epifania de um mistério" (DURAND, 1988). Nesse sentido, a educação fática não se atém ao puramente estético ou sensível, pois, mesmo envolvendo várias dimensões, tem a ética como fundamento principal, não se constituindo, pois, numa mera educação da sensibilidade. Em outras palavras, a educação fática requer um trabalho profundo com imagens simbólicas, programa de uma vida inteira que visa ao desenvolvimento da "base poiética da mente", numa cultura da alma que, em termos junguianos e hillmanianos (BADIA\& CARVALHO, 2002) não tem nenhuma conotação filosófica ou religiosa.

Para Hillman (1990), educação da alma significa um processo que vai do âmbito mais estreito do meu mundo humano empírico e suas preocupações pessoais em direção aos acontecimentos arquetípicos que colocam meu mundo pessoal e empírico numa moldura de significado.

Então, embora uma pedagogia do imaginário possa contribuir para o processo de individuação, para uma educação da alma, fertilizando-a com os hormônios do imaginário, não lhe cabe adentrar no reino da psique, cujos conteúdos autônomos nem sempre podem ser domados e humanizados.

Voltando à nossa questão, o que significaria, então, ensinar alguém a se comportar imaginativamente?

A primeira resposta que poderá vir à nossa mente é que se comportar imaginativamente é agir criativamente. Mas, o que se entende por criati- 
vidade?

De acordo com Hillman (1984), existem mais de 100 conceitos de criatividade. Provocativo como sempre, diz ele que converter o mistério do criativo em um problema a ser solucionado não é somente indecente, mas impossível. Apoiando-se em Jung, considera o criativo como um instinto, presente em todos os seres humanos, o qual não pode ser ensinado, na medida em que é uma energia originada além da psique. Então, nesses termos, uma pedagogia do imaginário não pode ser uma pedagogia da criatividade.

Uma pedagogia do imaginário não é um conjunto de técnicas ou estratégias de ensino e muito menos uma disciplina cujo conteúdo trate do imaginário ou da criatividade. Ao contrário, o imaginário precisa ser reconhecido e considerado em todas as atividades e disciplinas porque a lógica e o imaginário formam o tecido do espírito, o que significa integrar razão e imaginação.

Uma pedagogia do imaginário como metáfora, seria a porta-voz dos deuses que renascem. Ela é a metáfora do processo pelo qual o imaginário conduz a nossa vida, atribuindo-lhe sentido. E, nesse sentido, ela é sim uma educação fática, uma educação da alma, uma educação da sensibilidade.
Mas, como se valer dos seus recursos se a escola ainda se põe em guarda contra a imagem e o imaginário, que continua a ser um "passageiro clandestino" (JACQUETMONTREUIL, 1998), relegado a atividades desprestigiadas e sem importância ${ }^{4}$ ?

Em primeiro lugar, uma pedagogia do imaginário deve atingir os educadores porque, como dizem Wunenburger \& Araújo (2006), estes não podem existir sem deuses, isto é, sem narrativas que dêem sentido a sua ação educativa. A narrativa oferece uma razão de viver e na sua ausência se instaura um trauma psíquico. Postman (2005) diz que: "Mesmo que uma narrativa ponha a pessoa no inferno, é melhor estar ali do que não estar em parte alguma. Não estar em parte alguma significa viver numa cultura estéril que não oferece nenhuma visão do passado ou do futuro, nenhuma voz clara de autoridade, nenhum princípio organizador. Se esta é a cultura reinante na escola, para que educar?"

Que deuses poderão servir aos educadores? Que narrativas sobre a escola teriam suficiente ressonância para mobilizar os educadores, oferecendo a eles orientação, senso de continuidade, explicações do passado, clareza do presente e esperança para o futuro, enfim um propósito para a

\footnotetext{
${ }^{4}$ Enquanto os educadores apresentam inúmeros argumentos contra o imaginário, publicitários, políticos, mídias há longo tempo já fazem uso de uma "pedagogia da imagem e do imaginário", ativando símbolos, mitos, sonhos, estimulando zonas sensíveis, fantasmas, crenças (Jacquet-Montreuil, 1998).
} 
escolaridade (POSTMAN, 2005)? Seria este o papel das utopias?

Entendo que as narrativas sobre a escola estão atreladas às narrativas mais amplas veiculadas nos mitos, nas utopias, nas artes, na literatura, nos contos. São elas que podem fornecer os universos sócio-dramáticos para a emergência das imagens arquetípicas com toda sua carga simbólica. Imagens que, de acordo com Jung (1987), são caminhos virtuais herdados, que provêm do inconsciente coletivo e que transmitem as verdades e os valores fundamentais da humanidade.

Nos grandes relatos míticos, que recortam os homens aos outros homens, a palavra emerge das profundezas do ser. A pedra de toque é o seu enraizamento profundo no ser. Tanto os poemas como os contos podem "fornecer materiais e uma dinâmica à organização conjunta e complementar da imaginação e da razão" (JEAN, 1979, p. 53). Eles transmitem a cultura no sentido amplo do termo, ou seja, os mitos, as lendas, os costumes as técnicas, as religiões. Eles permitem às crianças e aos jovens reencontrarem as pulsões elementares dos devaneios humanos acumulados.

Uma pedagogia do imaginário ancora-se numa "razão simbólica" e requer uma linguagem que permita a comunicação simbólica, lembrando que o simbólico é aquilo que implica alguma coisa além do seu significado manifesto (JUNG, 2002).

Nessa perspectiva, seriam, entre outras, atribuições de uma pedago- gia do imaginário na escola:

1) estimular a imaginação, porque imaginar é se reconhecer. Se os alunos não são estimulados a imaginar não se reconhecem como alunos, como filhos, como membros de uma sociedade, como seres humanos;

2) ensinar o aluno a bem devanear, levar o aluno a tomar consciência do poder real do imaginário e de sua linguagem para se exprimir numa poética do cotidiano;

3) cultivar a sensibilidade e a afetividade como canais de abertura da imaginação em direção ao mundo.

\section{CONCLUINDO}

A reflexão empreendida leva-nos a concluir que se não é possível ensinar alguém a se comportar imaginativamente, é possível despertar a função imaginante, estimular o imaginário aprendente, embora não haja receitas para isso. Há apenas a certeza da sua possibilidade, mesmo que neste momento ela se nos afigure como uma utopia (MACHADO, 2004).

Na escola, em sua dimensão instituída, ela será uma contra-pedagogia, porque é preciso desaprender a pedagogia oficial. Por isso, por enquanto, ela só pode se manifestar nas fronteiras entre o instituído e o instituinte, o qual ainda não se deixou moldar pela razão dominante. Vocês podem me perguntar: há brechas? Claro que há, caso contrário não estaríamos aqui.

Mas, não há regras, receitas prontas para se trabalhar com o imaginá-

Olhar de professor, Ponta Grossa, 9(2): 215-227, 2006. $\overline{225}$ 
rio, pois, como diz Jean (1991), se a imaginação é a força que pode quebrar a rotina, uma pedagogia do imaginário é o poder de imaginar uma pedagogia sem hábitos, sem repetições, uma pedagogia constantemente ousada, "perigosa". Uma pedagogia que se inventa e que começa no momento em que somos capazes de compreender o imaginário dos outros. É a isso que chamo pedagogia do imaginário como metáfora.

Uma pedagogia do imaginário seria uma "didática da invenção", como diz Manoel de Barros (2001) em seu livro significativamente chamado $O$ livro das Ignorãças.

Para apalpar as intimidades do mundo é preciso saber:

a) Que o esplendor da manhã não se abre com faca

b) O modo como as violetas preparam o dia para morrer

c) Por que é que as borboletas de tarjas vermelhas têm devoção por túmulos

d) Se o homem que toca de tarde sua existência num fagote, tem salvação

e) Que um rio que flui entre dois jacintos carrega mais ternura que um rio que flui entre dois lagartos

f) Como pegar na voz de um peixe

g) Qual o lado da noite que emudece primeiro

etc

etc

etc
Desaprender oito horas por dia ensina os princípios.

\section{REFERÊNCIAS}

ARAÚJO, A. F.; ARAÚJO, J. M. Figuras do imaginário educacional, para um novo espírito pedagógico. Lisboa: Instituto Piaget, 2004.

BADIA, D. D.; CARVAlHO, J. C. P. Pessoa, grupo e comunidade. São Paulo: Plêiade, 2002.

BARROS, M. O livro das ignorãças. 10. ed. Rio de Janeiro: Record, 2001.

CAMPBELL, J. Tu és isso, transformando a metáfora religiosa. São Paulo: Madras, 2001.

CARVALHO, J. C. P. Imaginário e mitologia: hermenêutica dos símbolos e estórias de vida. Londrina: UEL, 1998.

DUBORGEL, B. Imaginaire et pédagogie. Toulouse: Privat, 1992.

DURAND, G. La création artistique comme configuration dynamique des estructures. Eranos-Jahrbuch, XXXV/ 1996, Zurich:Rhein-Verlag, p. 56-98, 1967.

DURAND, G. A imaginação simbólica. São Paulo: Cultrix/EDUSP, 1988.

L'Imaginaire, essai sur les sciences et la philosophie de l'image. Paris: Hatier, 1994.

As estruturas antropológicas do imaginário. São Paulo: Martins Fontes, 1997.

Campos do imaginário. Textos reunidos por Danielle Chauvin. Lisboa: Instituto Piaget, 1998.

$$
\text { Introduction á la }
$$


mythodologie. Mythes et sociètes. Paris: Albin Michel, 1996.

FÉTIZON, B. Sombra e luz: o tempo habitado. São Paulo: Zouk, 2002.

HILLMAN, J. Anima, anatomia de uma noção personificada. São Paulo: Cultrix, 1990.

O mito da análise, três ensaios de psicologia arquetípica. Rio de Janeiro: Paz e Terra, 1984

JACQUET-MONTREUIL， M. La fonction socialisante de l'imaginaire. Thèse (Doctorat en Sociologie) Université de Savoie, França, 1998.

JEAN, G. Les voies de l'imaginaire enfantin. Paris: Scarabée, 1979.

Pour une pédagogie de I'imaginaire. Tournai: Casterman,1991.

JUNG, C. G. O eu e o inconsciente. 18. ed. Petrópolis: Vozes, 1987.

. O homem e seus símbolos. 22. reimpressão. Rio de Janeiro: Nova Fronteira, 2002.

LIPOVETSKY, G. A era do vazio, ensaios sobre o individualismo contemporâneo. Barueri: Manole, 2005.

MORIN, E. O método 4: as idéias, habitat, vida, costumes, organização. Porto Alegre: Sulina, 2002.

Os sete saberes necessários à educação do futuro. 3. ed. São Paulo: Cortez, 2001

POSTMAN, N. O fim da educação: redefinindo o valor da escola. Rio de Janeiro: Graphia, 2002.

WUNENBURGER, J. J.; ARAÚJO, A. F. Educação e imaginário: introdução a uma filosofia do imaginário educacional. São Paulo: Cortez, 2006.
Encaminhado em: 05/11/06

Aceito em: 03/12/06

\footnotetext{
Olhar de professor, Ponta Grossa, 9(2): 215-227, 2006. $\overline{227}$
} 